\section{Extensión universitaria en Chile: discursos y prácticas sobrevivientes}

Boris González López

Facultad de Ciencias Sociales de la

Universidad de Playa Ancha, Chile.

bgonzal@upla.cl
A 100 años de la Reforma Universitaria de 1918 / Desafíos de gestión

RECEPCIÓN: 29/06/17

ACEPTACIÓN FINAL: 24/09/17

\section{Resumen}

Las universidades chilenas son herederas de un sistema político establecido en la década de 1980 por la dictadura que encabezó Augusto Pinochet Ugarte, quien fundó las bases de la educación de mercado, el principio de subsidiariedad, la competencia y la educación entendida como bien que se puede transar, vender y publicitar al mejor postor.

El fortalecimiento de este mercado de la Educación Superior ha enfrentado las funciones históricas de las universidades, su compromiso con la sociedad y con los sectores más desposeídos; frente a la necesidad de autofinanciamiento, mayor y más progresivo ingreso de estudiantes, venta de servicios, estrategias comerciales, que contradicen la naturaleza filosófica y política que explica la existencia de la Educación Superior como un potencial de bienestar y desarrollo para los países latinoamericanos.

Este artículo reflexiona críticamente sobre la naturaleza discursiva de la extensión, ofreciendo una lectura propositiva de un espacio epistemológico relevante — la ecología y el diálogo de saberes - para finalizar con una descripción de los principales modelos vinculantes que exhiben hoy las universidades chilenas.

\section{Palabras clave}

- Extensión universitaria

- Vinculación con el medio

- Dictadura cívico militar

- Ecología de saberes

- Modelos de extensión

\section{Resumo}

As universidades chilenas são herdeiras de um sistema político estabelecido na década de 1980 pela ditadura liderada por Augusto Pinochet Ugarte, que fundou as bases da educação no mercado, o princípio da subsidiariedade, da concorrência e da educação entendido como bom pode negociar, vender e anunciar para o melhor postor.

O fortalecimento deste mercado do Ensino Superior enfrentou as funções históricas das universidades, seu compromisso com a sociedade e com os setores mais desfavorecidos; emoposição à necessidade de autofinanciamento, renda maior e mais progressiva dos estudantes, vendas de serviços e estratégias comerciais que contradizem a natureza filosófica e política que explica a existência do Ensino Superior como potencial de bem -estar e desenvolvimento para os países latino-americanos.

Este artigo reflete criticamente sobre a natureza discursiva da Extensão, oferecendo uma leitura proposicional de um espaço epistemológico relevante: Ecologia e Diálogo do Conhecimento; para concluir com uma descrição dos principais modelos vinculativos atualmente exibidos pelas universidades chilenas.
Palavras-chave

- Extensão universitária

- Ligação com o meio

- Ditadura cívico -militar

- Ecologia do conhecimento

- Modelos de extensão
Para citación de este artículo

González López, B. (2017). Extensión universitaria en Chile: discursos y prácticas sobrevivientes. Revista + E versión en línea, 7(7), 110-121. Santa Fe, Argentina: Ediciones UNL. 


\section{Introducción: apertura crítica inicial}

El concepto "sobreviviente" no es utilizado al azar en el título de este artículo. Menos aún cuando su enunciación se realiza desde la experiencia de quien nació en los primeros años de una dictadura militar que durante 17 años (1973-1990) planificó y concretó un proceso de transformación radical, el cual, como metamorfosis kafkiana, derrumbó el sistema político, social y cultural de un país para inaugurar otro radicalmente opuesto. De allí que la idea de la sobrevivencia manifiesta una vitalidad, una resistencia a pesar de, un espacio de supervivencia que permaneció con vida aun cuando estuviera inmerso en el entramado jurídico e institucional que Augusto Pinochet, la elite cívico militar y Estados Unidos inauguraron para Chile. La democracia pactada que vino después tampoco resultó ser lo prometido. Más bien, durante los sucesivos gobiernos democráticos lo que se hizo fue administrar las bases heredadas, legitimando una forma de entender la función del Estado subordinada y subsidiaria de y a otros poderes y lógicas que hoy se entienden unitariamente desde la experiencia y la filosofía neoliberal.

Por eso, los lectores que en torno a este lugar se convoquen deben, al menos, considerar los siguientes criterios para su propio análisis: quien enuncia tiene 40 años. Es decir, nació en dictadura; ha sido observador y partícipe desde 1990 en adelante del paulatino deterioro del Estado, su burocracia e institucionalidad. Además, el espacio político desde donde se analiza es una universidad estatal y regional de educación superior de Chile. Por lo tanto, el espacio analítico está determinado por una precariedad histórica que comenzó con el desmembramiento de la gran universidad nacional -la Universidad de Chile - y que se ha profundizado, a pesar de los esfuerzos que cierto sector político, imbuido por la social democracia, ha realizado fragmentariamente.

También se ponen en tensión, observando en clave latinoamericana, las siguientes preguntas: ¿Existe una tradición extensionista, con evaluaciones y criterios claramente establecidos, que den cuenta de una continuidad histórica desde el Grito de Córdoba en adelante? ¿Es efectivo suponer dentro de la universidad tradicional latinoamericana procesos de transformación social, efectivos y radicales? ¿Han sido alguna vez nuestras universidades, entendiendo las asimetrías que existen, por ejemplo, entre universidades chilenas, argentinas, uruguayas, bolivianas, peruanas o brasileñas, lugares de revolución y movimientos sociales? ¿Es la extensión un motor relevante para la articulación institucional universitaria o somos limítrofes que viven en una burbuja que se alimenta de poética y retórica? ¿O estamos siendo elementos prescindibles de los efectivos procesos de transformación que viven sectores populares en todo el continente?

La realidad chilena puede ser un parámetro a considerar cuando se compare, analice y problematice, en general y en específico, la realidad de la educación pública latinoamericana. Pero principalmente puede resultar un indicador a considerar respecto de cuáles son los peligros de los avances de las políticas neoliberales y su transacción en un mercado que siempre querrá prosperar. A costa de las mayorías. A beneficio de las minorías. Como diría Galeano, "el mundo patas arriba".

Este artículo está estructurado del siguiente modo: se analiza el cambio de denominación conceptual de extensión universitaria a "vinculación con el medio", sus implicancias políticas e históricas; se describe, además, la irrupción de un conjunto de conceptos más o menos relacionado a la reflexión y producción teórica latinoamericana, más próximo o más distante a ideas importadas desde el mercado o la empresa. También se ofrece la primera sistematización de los modelos vigentes en Chile, aportando al debate que en esta materia se lleva adelante en el continente, para finalmente presentar una breve conclusión que da cuenta de los desafíos que tienen las comunidades universitarias chilenas en su compromiso con el país, la región y el mundo.

\section{Vinculación con el medio: entre el todo y la nada}

Este análisis surge de la investigación, de carácter nacional, denominada "Sistematización de experiencias innovadoras de vinculación con el medio", 1 que realizamos con un grupo de investigadores y ayudantes de investigación del Observatorio de Participación Social y Territorio de la Facultad de Ciencias Sociales de la Universidad de Playa Ancha, ubicada en la ciudad de Valparaíso, con el propósito de indagar en las características, cualidades y nudos críticos que adquiere la "tercera misión" o la "tercera función universitaria"(en caso de que sea posible enumerar la funcionalidad e importancia de unas sobre otras) en el existir actual, vigente, de las instituciones de educación superior chilenas. En ese marco, entre el 14 de abril y el 15 de septiembre de 2016 , efectuamos un total de 65 entrevistas semiestructuradas a autoridades y gestores de experiencias de 29 universidades estatales, tradicionales y privadas, considerando la diversificación que ha adquirido lo que se conoce como "el mercado de la
1) La investigación, realizada por los investigadores Pablo Saravia Ramos, Nelson Carroza Athens, Felip Gascón i Martín, Consuelo Dinamarca Noack,
Leyle Castro Vollaire, y quien escribe este artículo, Boris González López, dio como resultado final la publicación del libro Vinculación con el
Medio y Territorio: Heterogeneidad de modelos, prácticas y sentidos en las universidades chilenas, que sistematiza los hallazgos críticos más relevantes y una cartografía crítica de la experiencia de vinculación en Chile. 


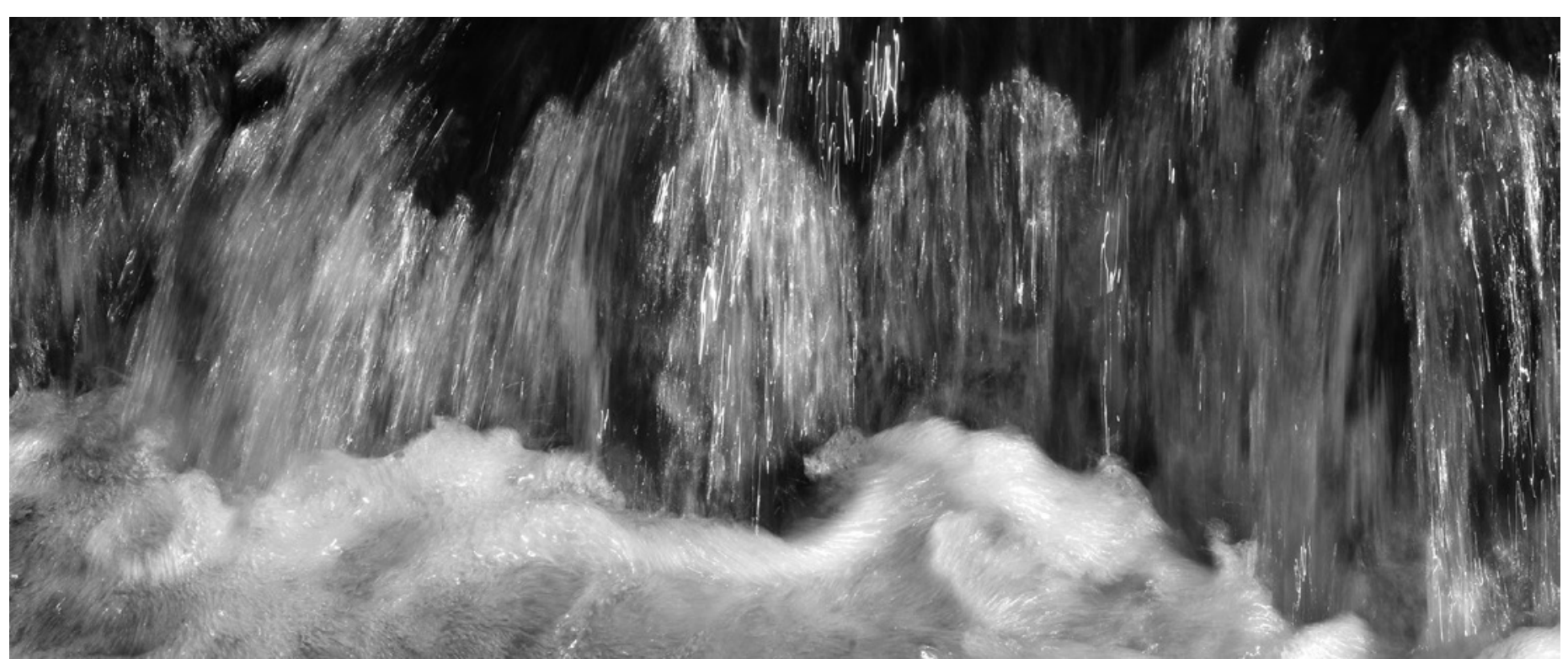

(C) Oscar Dechiara

educación superior", que desde 1990 en adelante comenzó a expandirse aceleradamente a partir del exponencial aumento en la creación de nuevas instituciones privadas (con escasa o nula fiscalización estatal), el aumento sustantivo de la matrícula universitaria y, paralelamente, la generación de un conjunto de becas, créditos bancarios y otros sistemas de pago que actualmente tienen a miles de estudiantes chilenos endeudados, cuestión que les significa un compromiso económico que se puede extender por décadas. Las interrogaciones saltan a la vista: ¿Esa realidad afecta la calidad de las funciones universitarias? ¿Es un indicador importante en el sistema de acreditación el nivel de endeudamiento con el que terminan los estudiantes chilenos? ¿O se mira para otro lado, por vergüenza a reconocer (o legitimar) el negocio en el que se transformó el sistema de educación superior chileno?

Volvamos al asunto directamente. El año 2006 resultó ser un año importante para el concepto de extensión universitaria, que históricamente había agrupado y cohesionado las experiencias territoriales de las instituciones chilenas de educación superior. Y es importante por una cuestión no menor: durante ese año se promovió y concretó el desaparecimiento de la conceptualización misma, al amparo de la Ley $N^{\circ} 20.129$ de Aseguramiento de la Calidad de la Educación Superior que, entre otras cuestiones, creó para Chile, la Comisión Nacional de Acreditación, CNA, cuya misión declara "verificar y promover la calidad de la educación superior mediante: la acreditación institucional de las universidades, institutos profesionales y centros de formación autónomos". El artículo 17 especifica que

"la acreditación se realizará en funciones específicas de la actividad de las Instituciones de Educación Superior. Las instituciones que se presenten al proceso deberán acreditarse siempre en los ámbitos de docencia de pregrado y gestión institucional. Adicionalmente, las instituciones podrán optar a la acreditación de otras áreas, tales como la investigación, la docencia de postgrado y la vinculación con el medio". (CNA, 2017)

Aparece así un nuevo reemplazante que toma su lugar, sin resistencia, en la cultura conceptual y discursiva de las universidades chilenas: la "vinculación con el medio", que deshistoriza y anula la memoria social y política de una institucionalidad con un fuerte componente simbólico para el país que tuvo sus gérmenes en 1843, año en que se fundó la gran universidad nacional: la Universidad de Chile.

Este cambio de denominación resultó ser un nuevo travestismo conceptual, característico de gestiones políticas que se precian de técnicas planificadas y eficientes pero que ocultan su fin último: ir fragmentando los avances en procesos que contienen naturalmente un fuerte impacto social ideológico, como todo lo relativo al trabajo territorial, la relación con los actores sociales o la relativización del verdadero resultado que tienen las disciplinas a la hora de pensar las comunidades, las regiones, las provincias, los países $y$, finalmente, el mundo. Es decir, cuánto de reproductivo hay en la epistemología y operatividad dominante, entendiendo que el sistema neoliberal se basa en una matriz extractivista que hace de las ciencias y la producción científica tecnológica, en general, un legitimador y justificador histórico permanente de las condiciones de vida de las personas y las comunidades (incluyéndonos, porque a veces nuestro "rigor" nos hace plantearnos fuera de contexto). Para los actores universitarios chilenos, de norte a sur del territorio, 
las experiencias con este cambio de nomenclatura resultaron significativas. $Y$ en este artículo son presentadas algunas de sus discursividades (resguardando la identidad de las fuentes) fruto de la investigación nacional —referida anteriormente- que concretamos junto a otros investigadores del Observatorio de Participación Social y Territorio. Estas pueden ser utilizadas como registros críticos o fotografías discursivas analíticas de ese momento (el paso de extensión a vinculación con el medio). Una de ellas da cuenta de la separación de la realidad regional latinoamericana:

"Lo que quisiéramos nosotros, también, es tener un lenguaje común con los países de América Latina, pues la mayoría utiliza el concepto de extensión cuando habla de esto, de relacionarse bidireccionalmente con la sociedad, desde los procesos académicos. Y ahí es donde estamos ahora, pasando desde este modo tradicional a un modo innovador, de construcción de diálogos significativos". (Entrevista 1)

Son diálogos o procesos significativos que para la política pública han tenido un rol marginal y secundario. Nunca central, porque la Ley Nº 20.129 de Aseguramiento de la Calidad de la Educación Superior hace una diferencia que impacta evidentemente en la valoración interna institucional de las universidades: clasifica en funciones que deben ser entendidas como obligatorias y otras como voluntarias. Entre las primeras están la docencia de pregrado y la gestión institucional, colocando un parámetro bastante limitado de comprensión para el sentido del ser y hacer vida universitaria en su integralidad. Entre las segundas están la vinculación con el medio, la docencia de posgrado y la investigación.

Esta clasificación tiene variadas interpretaciones. El desequilibrio en las valoraciones específicas de las funciones universitarias (a propósito de la "tercera" misión), que en un panorama como el chileno no resultan cuestión menor: desde la asignación de las cargas académicas, financiamiento de proyectos, valoración para la jerarquización; van sosteniendo un proceso de precarización continuo y estable de las funciones voluntarias, principalmente la relacionada a la filosofía extensionista o, pensando en clave chilena, la vinculación con el medio. Ni la docencia de posgrado ni la investigación sufren igual discriminación (técnica e ideológica) porque ambas poseen sus propios procesos de regularización jurídicos, políticos e institucionales, que hacen que las universidades, para la captación de mayores y más prolongados recursos, opten por acreditarse en dichas áreas.
Es decir, acceder al sistema nacional e internacional de becas para los posgrados, mejorar los índices en la publicación de revistas científicas con indexación y corriente principal, facilitar la postulación a proyectos internacionales de investigación, son otros condicionamientos que hacen que las universidades promuevan, queriéndolo o no, un sistema de competencia que es el corazón del "mercado chileno de la educación superior" y la relación que se establece con otros sistemas de educación superior del continente y el mundo, en virtud, por ejemplo, de las pautas que dictamina la OCDE o el Banco Mundial. Así, las universidades, independientemente de su naturaleza jurídica, sean estatales, tradicionales o privadas, están entre los principales avisadores del mercado publicitario chileno e invierten millones de dólares anualmente, cifras casi tan cuantiosas como la deuda que sigue en aumento de miles de estudiantes chilenos. ¿A alguien le resulta contradictorio esto? Y ese avisaje va orientado a captar la mayor cantidad de estudiantes posible en los procesos de admisión que las universidades realizan durante todo el año, tratando "de vender sus servicios" a partir de su experiencia, historias, discursos desarrollistas, años de acreditación, áreas de acreditación, carreras, innovaciones y toda una serie de otras discursividades orientadas a vender un producto, como quien vende cualquier cosa. Como lo afirmó Sebastián Piñera ${ }^{2}$ alguna vez, "la educación es un bien de consumo". Así, la máquina se mantiene funcionando y en plena vitalidad.

Pero los cuestionamientos a esa vitalidad persisten en las universidades chilenas. No han sido extirpadas totalmente la tradición ni las raíces que son enunciadas como sobrevivientes, porque en la memoria, en la genealogía de las discursividades y prácticas, existe en las voces de académicos universitarios ese sentido de experiencia y pertenencia histórica compartida. Así lo demuestra este relato, que utiliza la palabra "siutiquería" para centrar una crítica que pretende enfatizar en un travestismo conceptual carente de argumentos:

"A mí me gusta la palabra extensión. No sé de dónde viene esta siutiquería de la vinculación con el medio. Por eso, reivindico a la extensión universitaria puesto que nos pone en contacto con la población y con la posibilidad de que te tiren tomates. Sin embargo, debemos tener presente que al poner en contacto el conocimiento académico con el conocimiento popular el primero se robustece, aún cuando seamos criticados por nuestro alejamiento, por habernos quedado en las nubes de los intelectuales". (Entrevista 2) 


\section{6}

El término "vinculación con el medio" fue producto de toda una renovación discursiva que combinó elementos de la tradición extensionista chilena y latinoamericana (sobrevivientes), con otras conceptualizaciones provenientes del mundo de la empresa y la economía
La universidad mira como espejo a la sociedad y viceversa. Por lo tanto, esta fase neoliberal agresiva, principalmente durante los últimos 40 años, no ha logrado borrar el sentido de lo público, sustentado especialmente en la tradición que forjó la Universidad de Chile, no solo en la educación superior sino en el establecimiento del sistema nacional de educación pública (en sus niveles primarios y secundarios) y que tuvo en el país, desde la segunda mitad del siglo XIX, un referente de particular importancia para el continente y que se fue nutriendo con los procesos políticos que abrieron la ruta, a partir 1900, para la formación de partidos populares, movimientos sindicales y sociales, que redefinieron el mapa político hegemónico dominado por una elite masculina, blanca y oligárquica, que vio en sucesivas sublevaciones un peligro latente que había que eliminar (Salazar, 2011). Así, la universidad, se transformó en campo de batalla y disputa de ideas entre la década de 1960 y 1970, y logró recuperar los principios enunciados hace cien años por los estudiantes de Córdoba en el Manifiesto Liminar, en importantes reformas universitarias vividas en Chile en 1967, cuyo corolario político fue la elección de Salvador Allende en 1970. Tres años duró el ascenso popular y la contextualización de una universidad pública en sintonía con el contexto que Chile experimentó (a propósito del "efecto espejo").

Lo que vino después fue esa metamorfosis kafkiana que nos hace explorar entre discursos y prácticas sobrevivientes, que denotan, como esta perspectiva aportada por otra académica, una crítica permanente al modo en cómo se administró el Estado, una vez recuperada la democracia, específicamente en lo que se entendió como "el milagro de la economía chilena", que se desenvolvió apoyada por un fuerte aparato comunicacional en poder de los grandes grupos económicos del país. Aquí sus palabras:

"Somos un país (Chile) que históricamente, a nivel institucional, ha vivido de las modas discursivas y de los ejemplos foráneos. Fuimos, según algunos de nuestros conspicuos políticos, durante la década del '90 'Ios jaguares de América', a propósito de un éxito económico bien falso, mentiroso y doble estándar. Antes, a algunos, les gustaba llamarnos 'los ingleses de América', por un tono de sobriedad que ocultaba la pleitesía que generalmente, nuestra clase acomodada, le ha rendido a las grandes potencias del mundo. Hoy, esta idea de vinculación con el medio expresa una voluntad vacía que nos separa de una tradición mayor, sin que las universidades, sus académicos o estudiantes, se interrogasen en lo más mínimo. Vamos detrás de algunas migajas de recursos que permitan poner en pie a nuestras instituciones". (Entrevista 3)

\section{Saberes: espacio para redefiniciones y prácticas}

El término "vinculación con el medio" no llegó aislada e individualmente. Fue producto de toda una renovación discursiva que combinó elementos de la tradición extensionista chilena y latinoamericana (sobrevivientes), con otras conceptualizaciones provenientes del mundo de la empresa y la economía, configurando una nueva Torre de Babel que cada cierto tiempo va renovando, naturalizando y deshistorizando aquellas prácticas y experiencias que tienden a tensionar la estructura jerárquica de la gestión y el sentido más genuino del hacer y pensar universitario. Particularmente, en Chile, donde, entre otras cuestiones relevantes, no se ha recuperado la participación democrática para la toma de decisiones en las universidades y es todavía dominio de un grupo reducido de académicos que determina el rumbo que siguen las instituciones.

Con este panorama, los conceptos que rondan al de vinculación con el medio surgen desde dos vertientes principales: la primera, relacionada con aquellos términos que continuamente está difundiendo la literatura especializada; y, en segundo lugar, desde las convocatorias a concursos públicos, en su condición de instrumentos de política pública, que van orientando algunos 
procesos incipientes que hacen que las universidades intenten ganar en estas competencias, asegurando recursos frescos escasos en el actual panorama del sistema de educación superior, con especial urgencia en las instituciones que, se supone, están al amparo del Estado. Esta académica despliega su discurso crítico sobre la idea de competencia:

"El modelo parte de la competencia. Cualquier idea de cambio, que enriquezca el patrimonio de las universidades y de las organizaciones sociales, debe canalizarse en fondos externos que surgen desde la política pública. Los convenios de desempeño regionales, por ejemplo, son un buen ejemplo de lo que ocurrió: se abrió una convocatoria con palabras claves como innovación y generación de conocimiento compartido, y todos los que concursamos nos alineamos en esa discursividad. Queríamos ganar y para ello había que hablar en esa nomenclatura. No importaba si compartíamos o no esas definiciones. Queríamos recursos, que siempre escasean en nuestra instituciones, para acercarnos más a los territorios". (Entrevista 4)

Las voces que provienen de esa torre, esbozan toda una batería conceptual que vamos repitiendo en cada conferencia, jornada, charla o concurso, que nos permita asegurar algún tipo de beneficios, entendiendo, por supuesto, que hoy la labor extensionista es la hermana menor, y escasamente reconocida, de las funciones universitarias. De algún modo, es el hijo ilegítimo de un contrato conyugal donde los intereses están focalizados en otras tareas, prácticas y estructuras. En esa relación y contextos, se repiten en las discursividades de los actores universitarios conceptos como: bidireccionalidad, reciprocidad, diálogo de saberes, saberes universitarios y saberes populares, modelos de replicabilidad, conocimiento situado, responsabilidad social universitaria, aprendizaje en servicios, entre muchas otras enunciaciones, que intentan alinearse con la nueva conceptualización, más acá o más allá, ideológicamente, del espíritu transformador que animó hace cien años a los estudiantes de Córdoba.

"En este sentido, es necesario reconocer que 'extensión universitaria' es un referente nodal de la genealogía del movimiento de Reforma Universitaria ocurrido en América Latina en la primera mitad del siglo XX, que tuvo en los sucesos de Córdoba de 1918 uno de sus hitos." (Carlevaro, 1998:8)

Un distanciamiento que este sobreviviente llamado vinculación con el medio está problematizando. Con todas las contradicciones que carga consigo, motivado por hacer de la crítica el primer ejercicio, elemental, básico y propositivo, de la práctica extensionista. En ese recorrido, otro concepto que ha ganado adeptos, el de Responsabilidad Social Universitaria (RSU), que es entendido por los actores universitarios como principio y práctica ética que define parte importante del quehacer de las universidades. Lo paradójico, analizando las representaciones de actores institucionales y de experiencias, es que la RSU entra con facilidad en las discursividades políticas y técnicas de las universidades, en sus documentos estratégicos (misión, visión), en su filosofía corporativa, y es enunciada incansablemente en los espacios de ratificación de la identidad institucional.

La dicotomía resulta elemental: apelar a un concepto cuyo origen se sitúa en las lógicas del mercado, en tanto que es este mismo actor el que ha distorsionado la naturaleza de la institucionalidad educativa chilena, sus fines y propósitos.

"Se ha consolidado un modelo que si bien es tributario de los mejores ideales de la universidad latinoamericana, rescatando algunos ámbitos y espacios muchas de sus más trascendentes esencias y más caras tradiciones, se ha orientado hacia una tendencia profesionalizante y tecnocrática que en general no prioriza la formación integral y humanista de los universitarios." (Tommasino, 2010:135)

De este modo, se afianza la idea de la universidad como un campo en disputa permanente, que va avanzando o retrocediendo a medida que los Estados y los gobiernos de turno van disputando ideológicamente ideas de universidad que instrumentalizan sus propósitos, sus capacidades, sus fortalezas y debilidades. Los discursos, los documentos estratégicos son, también y por lo tanto, espacios de confrontación, tal y como lo señala este académico de una universidad de la región central de Chile:

"Las palabras tienen historia. Están dentro de nuestra cultura universitaria por algo. Están cargadas de ideología. Y si en esta pulsada lo que ha ganado ha sido el lenguaje técnico, que se precia para sí de objetivo, que viene acompañado por la 'formación en competencias' y todos los lineamientos de las organizaciones internacionales; lo que habita en la otra vereda es una tradición que habla de cooperación, de saberes compartidos, de extensión crítica. Es también una disputa que habita en el decir y que no está perdida o ganada del todo. Los conceptos más propios de nuestras raíces también pueden habitar en la cultura universitaria, con indicadores, reconocimientos de horas, inversión, planificación. Se trata de volver a disputar un anhelo, o una utopía, si se quiere, que situaba a la universidad como una generadora de respuestas a la cuestión social que ha caracterizado a nuestro continente. Han cambiado las fachadas, son más modernas, pero por dentro, la intimidad, las fortalezas y las carencias siguen siendo la misma". (Entrevista 5)

En esta permanente circulación discursiva, propia y arraigada a la metamorfosis continua que vive el lenguaje disciplinar y académico, se accede a una puerta (no es única, por supuesto) que abriría 
nuevamente ese reconocimiento a la historia, tradición y luchas presentes y pasadas de este continente. Se trata de la "ecología de saberes" (De Sousa Santos, 2014) y su paradigma político de comunicación —el diálogo de saberes—que sintetiza, reúne, explora, problematiza y deconstruye el modelo de universidad vigente, su estructura jerárquica, sus preferencias epistemológicas, su relación con los procesos formativos y sus prioridades curriculares, de la mano con los aportes que durante todo el siglo $X X$ realizaron pensadores latinoamericanos fundamentales. Otro académico enfatiza en la irrupción de este espacio epistemológico:

"La ecología de saberes aparece como una posibilidad de salir de esa torre de marfil que cada tanto aparece entre nosotros y en nuestras prácticas, en actividades académicas y en informes que debemos presentar al Ministerio de Educación o a la Comisión Nacional de Acreditación. Una torre que mira desde las alturas para iluminar a los que viven en la oscuridad. Es decir, transitamos desde el iluminismo al oscurantismo, en pleno siglo XXI, cuando reconocemos que no somos los únicos poseedores de la verdad y del saber, si es que alguna vez lo fuimos. Que hay modos de aproximarse al conocimiento, a la verdad, que brotan desde memorias arraigadas en lo social, en lo popular, en pueblos originarios, que todavía no entran con fuerza a enriquecer el saber de la universidad. Una ecología permite la convivencia". (Entrevista 6)

La idea de ecología permitiría aperturas relevantes. Entre ellas, las más destacadas: disponer de un espacio epistemológico propio y original, que reconoce la tradición del saber científico como un patrimonio fundamental e innegable para el desarrollo humano, que no debería convivir como cúspide o síntesis de un modo de producción y difusión de saber único y totalitario. Supone una o más contrapartes generadoras de saberes, como ejercicio dialéctico constitutivo del pensamiento humano, basado en la experiencia histórica, en el devenir, en constructos interpretativos que se sitúan fuera del método científico, del ensayo y error, y, finalmente, de una tradición de pensamiento occidental, patriarcal, colonial y hegemónico.

La ecología, por tanto, es pluralidad, heterogeneidad y diversidad, como síntesis de un conocimiento ancestral negado, violentado e invisibilizado, que reside (otra vez aparece la idea de sobrevivencia) en pueblos originarios que han resistido a las independencias republicanas blancas y coloniales, y de cuyo mestizaje se han ido acumulando prácticas, experiencias y conocimientos transmitidos de generación en generación, de lucha en lucha, de contextualización en contextualización. Esta ecología, por tanto, se caracteriza por ser esencialmente contextual, móvil y heredable. Habita, de algún modo, en cada uno de nosotros.

"Por lo tanto, también son reflejo y una traducción viva de su propio recorrido de dominación que los ha situado históricamente en una posición subalterna respecto del conocimiento científico universitario. Su naturaleza y fisonomía encarna un proyecto de liberación epistémica, centrado en su reconocimiento y proyectado hacia potenciales instancias de diálogo con las otras esferas y centros de producción de conocimiento." (Saravia, 2017:67)

Representa la posibilidad de repensar, reconfigurar y refundar la universidad en relación al mundo que se vive, a las crisis que están desplegándose como resultado de procesos históricos que no pueden continuar pasando frente a los ojos de la educación superior pública como si nada. La crisis del Estado, la idea de república, el sentido y praxis de la democracia, el modelo productivo, las migraciones, las guerras tecnológicas, la agroindustria, la minería, la educación, las nuevas expresiones del imperialismo, los nuevos modos y estrategias de dominación, la desaparición forzada de personas, el narcotráfico, el tráfico de armas; el hambre; las injusticias sociales. Todas, acumulaciones discriminadoras que impugnarán directamente a la institucionalidad de la universidad más temprano que tarde. ¿Qué papel ocupa, entonces, la vinculación con el medio (o la extensión) en este involucramiento, traducción y lectura del mundo en que vivimos?

Una respuesta pueda habitar en esa idea de ecología.

"Como una epistemología posabismal, la ecología de saberes, mientras fuerza la credibilidad para un conocimiento nocientífico, no implica descreditar el conocimiento científico.

Simplemente implica su uso contrahegemónico. Ese uso consiste, por un lado, en explorar la pluralidad interna de la ciencia, eso es, prácticas científicas alternativas que han sido hechas visibles por epistemologías feministas y poscoloniales y, por otro lado, en promover la interacción e interdependencia entre conocimientos científicos y no-científicos." (De Sousa Santos, 2009:196)

Esta idea de ecología de saberes exige una redefinición y relectura de los procesos universitarios en todas sus fases. Desde asumir la estrategia de relación como un proceso estratégico fundamental, horizontal y abierto a nuevas formas de entendimiento y ejecución de la participación y la democracia, bajo una contextualización plural, que supera las dos partes: es decir, la universidad, como un gran bloque y, después de ella, todo lo demás. Por eso, el concepto de bidireccionalidad que se repite en el discurso de los actores universitarios chilenos y en los documentos orientadores que han emanado de "comités de expertos" reduce la importancia del reconocimiento, la caracterización heterogénea por naturaleza y las complejidades identitarias e históricas que son parte constitutiva del proceso de extensión. Es importante, por lo tanto, hablar de procesos dialógicos, heterogéneos y plurales que visibilizan identidades, modos de operación, historicidades, estrategias de producción y resistencia. 


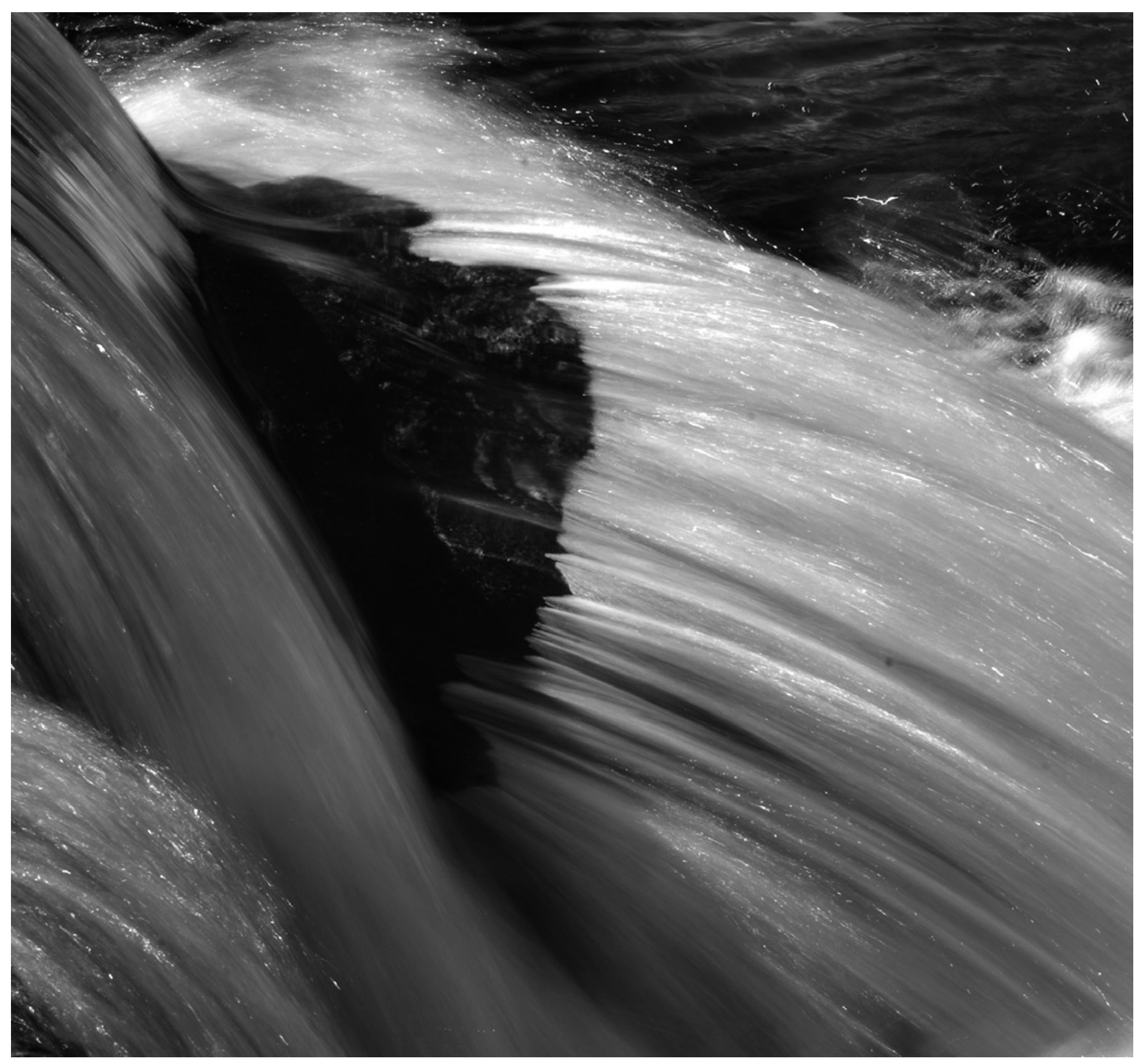

(c) Oscar Dechiara 
Así, los actores universitarios van entendiendo en la idea de vinculación una naturaleza, una forma sin la cual es imposible constituir la universidad del siglo XXI, que necesitará como nunca antes adecuar sus procesos a los desafíos de un mundo que vive una encrucijada mayor. Un ethos vital, en palabras de esta académica:

"Además de responder a las necesidades que existen ante respuestas científicas que nosotros queremos dar, también nos alimentamos y alimentamos nuestra formación a partir de lo que observamos en el medio. Entonces es una forma de vincularnos, es una forma de generar estrategias de sustentabilidad y auto sustentabilidad. Es una manera de legitimarnos. O sea, mi visión es que la universidad es solo un medio y únicamente tiene sentido en la medida que sirve a la sociedad y a las personas. Por tanto, la vinculación con el medio es casi un ethos". (Entrevista 7)

La construcción compartida de conocimientos es producto del diálogo de saberes y parte de una ecología donde la universidad se dispone a problematizar sobre sus propios modos de gestión, producción y puesta en valor de todo cuanto cree saber, abierta a la recepción de la crítica sistémica planteada: habitar un espacio físico y simbólico, la ecología de saberes, que propone un nuevo modelo respecto a la torre de marfil, que privilegia una relación cooperativa por sobre una vertical; que termina con la relación tutelar y asistencial hacia un reconocimiento de los otros como productores de saberes y conocimientos. Como señalaba Aimé Césaire, "un universalismo donde quepan todos los particulares" (2016). Allí habita ese ethos.

\section{Modelos emergentes: entre el ensayo y el error}

Uno de los hallazgos más relevantes de la investigación que realizamos a nivel nacional fue la caracterización o tipología de experiencias de extensión universitaria o Vinculación con el medio, presente de norte a sur de Chile en universidades estatales, tradicionales y privadas. Para realizar ese trabajo, utilizamos las siguientes dimensiones para la reflexión crítica y analítica: heterogeneidad; hibridez; territorialidad; convivencia entre lo convencional y lo emergente.

La heterogeneidad en la comprensión del concepto de Vinculación con el medio, en el marco del proceso de desarraigo que he narrado, ha abierto un campo altamente polisémico, relacionado a las características, asociatividades y contenidos propios de esta función. En este sentido, pese a lo que pudiera entenderse como una lógica institucional homogénea y que persigue la estandarización, es posible reconocer formas, prácticas y sentidos que van vinculados al reconocimiento de diversidades y complejidades propias de estas prácticas. Más que pretender reconocer la existencia de modelos puros en la construcción de este tipo de experiencias, se trata de visibilizar la condición híbrida y hasta coyuntural de procesos determinados, tanto por epistemologías científicas en crisis, resistencia y transformación, como por dinámicas histórico socio culturales y territoriales que, a menudo, tensionan y son tensionadas por la multiplicidad y falta de sintonía entre las políticas públicas, las prácticas y procesos universitarios y la realidad de los procesos y tiempos sociales. Otra de las dimensiones relevantes para cruzar y aproximarse a estas tipologías o modos de ser y hacer extensión universitaria es la territorialidad, entendida como el patrimonio concreto presente, con elementos que emergen o se heredan sobre cuestiones cotidianas e históricas, que van fundando y estableciendo relaciones sociales, culturales, políticas y económicas, entendidas no como un desarrollo lineal sino que eminentemente móviles y zigzagueantes. Las evidencias emanadas de esta cartografía nacional que realizamos, muestran un intento emergente por distanciarse de la visión más clásica del paradigma extensionistadifusionista, aproximándonos a intuir una modificación epistémica y política en los modos de comprensión en las interacciones, demandas, confianzas y desconfianzas de las comunidades y la apropiación de sus territorios.

En este ejercicio de comparación analítica y relacional logramos cruzar las siguientes variables: espacio epistemológico para la generación de conocimiento compartido; implementación de redes; implementación de metodologías más o menos tradicionales; y la evaluación de los impactos fuera o dentro de la universidad. Así, logramos aproximarnos a modelos de trabajo que conviven entre sí, tomando elementos de uno y otro en un umbral amplio y transfronterizo, como se expresa en el Cuadro $\mathrm{N}^{\circ} 1$ : El modelo convencional e instrumental se soporta sobre la lógica transferencista asistencial que prioriza la entrega unilateral de bienes nobles a la comunidad, donde es posible apreciar los roles del que sabe y del que necesita ser iluminado por un tipo de conocimiento propio del saber científico hegemónico. Hay, por lo tanto, una nula aproximación a la idea de escucha-habla y una protección natural de la relación tutelar generada desde las alturas de la torre de marfil en una estrategia de gestación del conocimiento funcional-operativo del extractivismo académico o epistémico, que pretende invisibilizar a los saberes populares para después legitimarlos a través de los discursos especialistas de los expertos (Ortiz-Riaga y Morlaes-Rubiano, 2011).

Su mecánica de funcionamiento se asienta en redes de tipo extensionista difusionista y en una praxis metodológica sustentada en la planificación estratégica, propia de los procesos de acreditación y medición de la calidad sostenida sobre el marco lógico y la medición de indicadores, que excluyen otros modos de medición alternativos y subalternos. En esta primera agrupación discursiva se entiende la formación universitaria como un proceso 
Cuadro $\mathrm{N}^{\circ}$ 1: Modelos vigentes de vinculación con el medio. Extensión en universidades chilenas

\begin{tabular}{|c|c|c|c|c|c|}
\hline $\begin{array}{l}\text { Dimensiones } \\
\text { modelos }\end{array}$ & $\begin{array}{l}\text { Prácticas de vinculación } \\
\text { con el medio (Extensión) }\end{array}$ & Redes & $\begin{array}{l}\text { Generación de } \\
\text { conocimiento compartido }\end{array}$ & Impactos & Metodologías \\
\hline $\begin{array}{l}\text { Convencional e } \\
\text { instrumental. }\end{array}$ & Extensión tradicional. & $\begin{array}{l}\text { Redes de extensión } \\
\text { difusionista }\end{array}$ & Funcional/operativa. & $\begin{array}{l}\text { Relaciones con la } \\
\text { comunidad esporádicas. } \\
\text { Prácticas académicas } \\
\text { convencionales. }\end{array}$ & Planificación estratégica. \\
\hline $\begin{array}{l}\text { Reformismo } \\
\text { híbrido. }\end{array}$ & $\begin{array}{l}\text { Vinculación como } \\
\text { experiencia académica. }\end{array}$ & $\begin{array}{l}\text { Redes de extensión } \\
\text { difusionista. } \\
\text { Redes de alianzas } \\
\text { estratégicas. }\end{array}$ & $\begin{array}{l}\text { Punto de encuentro/ } \\
\text { facilitador. }\end{array}$ & $\begin{array}{l}\text { Relaciones con la } \\
\text { comunidad. } \\
\text { Procesos de aprendizaje. } \\
\text { Prácticas académicas. }\end{array}$ & $\begin{array}{l}\text { Incubadoras. } \\
\text { Planificación estratégica. } \\
\text { Metodologías colaborativas. }\end{array}$ \\
\hline $\begin{array}{l}\text { Emergentes } \\
\text { participativas. }\end{array}$ & $\begin{array}{l}\text { Vinculación con el medio } \\
\text { como extensión crítica. }\end{array}$ & $\begin{array}{l}\text { Redes para el buen } \\
\text { vivir. }\end{array}$ & $\begin{array}{l}\text { Mirada arqueológica. } \\
\text { Mirada política. } \\
\text { Mirada como espacio } \\
\text { articulador y transformador. }\end{array}$ & $\begin{array}{l}\text { Curricularización. } \\
\text { Estructura universitaria. } \\
\text { Relaciones permanentes } \\
\text { con la comunidad. }\end{array}$ & $\begin{array}{l}\text { Investigación Acción/ } \\
\text { Participativa (IAP). } \\
\text { Construcción de umbrales } \\
\text { de participación. }\end{array}$ \\
\hline
\end{tabular}

Fuente: González López et al. (2017:198).

de acompañamiento secundario, fragmentario y discontinuo, con un valor marginal en el entramado estructural de las universidades y los actores que viven en, dentro y fuera de dicha institucionalidad. Es decir, se trata de un contexto precario en el reconocimiento orgánico de la tarea extensionista.

El segundo modelo, que hemos denominado "reformismo híbrido", visibiliza más prolíficamente la vinculación con el medio o extensión universitaria como reconocimiento de la experiencia académica. En los discursos universitarios son valoradas experiencias como tesis de pre y posgrado; prácticas profesionales; aprendizaje en servicios, entre otras conceptualizaciones características de la rica polisemia conceptual propia del ámbito. Su base epistemológica se amplía sobre una valoración significativa de la idea de generación de conocimiento compartido, erigida sobre una perspectiva arqueológica que promueve, fortalece y facilita el redescubrimiento y reconocimiento de lo popular como germen, patrimonio y perspectiva de los saberes populares, aceptados, a priori (como condición inicial para les gestión y promoción de un conocimiento plural) como promotores de un función fundamental: transformarse en punto de encuentro facilitador para los procesos transformadores que se gestionan colectivamente.

La estrategia de operatividad de este modelo funciona a nivel relacional sobre redes que operan como mercado de servicios, con un actor especializado con influencia para la toma de decisiones desde la administración burocrática e institucional. Por lo tanto, se establece una lógica centralizada y jerárquica, que privilegia el vínculo con organizaciones formales y actores instituidos al amparo del Estado o de organizaciones privadas. Su práctica metodológica es móvil y flexible entre metodologías de incubación, planificación estratégica y metodologías colaborativas, que optan por una u otra dependiendo del caso y las lecturas de los contextos, el desarrollo de productos y alta selectividad de beneficiarios, tanto en el ingreso al modelo como durante sus distintas etapas de desarrollo. Las colaborativas permiten la participación de diversos actores, el trabajo en grandes grupos y la construcción de agendas comunes. Estos elementos y factores facilitan la descripción más transparente tanto de los impactos internos como de los externos relacionados con la formalización de cursos, programas, seminarios y diplomados que entienden e incorporan a los actores territoriales como parte fundamental del modelo. Se avanza incipientemente a curricularizar la vinculación con el medio o extensión universitaria, siendo también ampliamente heterogéneas sus expresiones en las universidades chilenas y latinoamericanas.

"Un repaso a esta gran diversidad de actividades evidencia que la extensión se construye como un campo del quehacer universitario sumamente heterogéneo, siendo parte del amplio espectro de la vinculación social de las universidades, la extensión adquiere mayor o menor diferenciación conceptual (identidad) según diferentes contextos." (Tommasino y Cano, 2016:9)

La tercera modelación discursiva se aproxima, conscientemente, a lo que parte de la literatura latinoamericana entiende como extensión crítica. Es decir, una experiencia formativa instaurada a nivel curricular que se integra a los programas formativos de todos los estudiantes, de todas las disciplinas, y también a las prácticas docentes e investigativas, en su estructuración y reconocimiento 
global a nivel institucional, capaz de levantar espacios universitarios traductores del saber situado en todos las locaciones del quehacer social y de generación progresiva, sistemática y permanente de conocimientos vinculantes, compartidos y plurales. El formato relacional reconoce, desde un inicio, la toma de decisiones compartidas, desde una perspectiva epistemológica que combina las miradas arqueológicas, políticas y articuladoras para la generación de conocimiento y saberes compartidos entendidas unitariamente en el marco de un todo, que identifica múltiples modelos que asumen y se hacen cargo de los desafíos locales, regionales, nacionales y globales (Tuhiwai, 2016). Su meta se ancla y aprehende, entonces, de una función más transformadora y radical, que acepta como parte de su esencia las contradicciones o tensiones propias del lugar ideológico y práctico que ocupa, encarnando un proyecto de liberación epistémica cuyo motor productivo y transformador hace que la universidad opere como bisagra o puente de múltiples vías y direcciones, promoviendo como parte de la filosofía universitaria el intercambio de saberes y prácticas. La renovación o transformación radical de la universidad, desde esta perspectiva, es el modo de evitar y sobrevivir a la crisis que la institucionalidad contemporánea, en general, sufre, debido, precisamente, a la distancia exponencial que históricamente ha ido acrecentando la burocracia tanto pública como privada.

Son redes para el buen vivir el modo relacional que, también de modo emergente, destacan los actores universitarios en sus discursividades, valorizando la potencialidad de las universidades para la toma de conciencia de los conflictos que afectan a la sociedad, a partir de la reflexión analítico crítica, la generación de discursividades públicas que acentúen la democratización liberadora de los saberes, su incorporación y sistematización, su traducción, si fuera necesario, para un accionar transformador de estructuras institucionales y prácticas sociales, donde las metodologías de trabajo resultan elementales, cuando asumen el desafío de innovar, de ser activo-participativas, basadas en relaciones horizontales, descentralizadas, con presencia y permanencia en los territorios.

Entre ellas están metodologías comprometidas con el devenir latinoamericano, como son la Investigación Acción Participativa (IAP) o la Investigación Militante, y de un modo progresivo, la construcción de umbrales de participación, que es diseñado en espacios de concertación entre la universidad y actores y organizaciones territoriales heterogéneas.

"El impacto más relevante en este discurso es la cohesión integral de un modelo de extensión crítica que entra, de modo emergente, a disputar los saberes legitimados al interior de la universidad con aquellos provenientes de los territorios, por intermedio de la validación política y orgánica de instancias institucionales que formalizan esta experiencia a nivel micro y macro: desde asignaturas pensadas desde y con el territorio; hasta escenarios institucionales que funcionan como traductores en doble sentido; pasando por las horas asignadas a los labores docentes, estudiantiles y administrativas de la Vinculación con el medio; $y$ teniendo presente que en ese ejercicio de diseño y liberación los actores estratégicos del territorio también influyen en sus memorias, prácticas y saberes a nivel de pares." (González y Saravia, 2017:145)

\section{Conclusiones}

Este ejercicio analítico demuestra un tipo de sobrevivencia que ha transitado por décadas convulsionadas, que representaron históricamente para Chile una involución desde la llegada del régimen del terror de Pinochet y sus aliados nacionales e internacionales, con miles de detenidos desaparecidos, ejecutados políticos, sumarios entre colegas, expulsión de estudiantes y un sinnúmero de otras historias que necesariamente se deberán escribir para proteger y preservar la memoria individual y colectiva. En esas contradicciones habita la extensión universitaria, que resultó sobrevivir sin que necesariamente esta vitalidad asegure eternidad: los enemigos hoy no visten uniformes, aunque pueden volver a hacerlo. Están administrando un modelo, lucrando con él, a costa de miles de estudiantes, familias y actores sociales que esperan que la Universidad sea lo que dice ser en sus documentos estratégicos, filosofías corporativas, buenas intenciones y un conjunto de luchas que nos acompañarán.

En los discursos de los actores universitarios chilenos existe un reconocimiento fundamental: se asume como tarea insustituible la vinculación con el medio situada desde las contradicciones ya dichas y reconociéndonos como extensionistas que habitan un campo o escenario en permanente disputa. Por eso, la metamorfosis discursiva fue una respuesta para continuar aumentando 
las distancias que separan al modelo chileno de otros en Latinoamérica, pero no fue la suficientemente fuerte para borrar, eliminar o hacer desparecer, como en los vuelos de la muerte que perfeccionaron las dictaduras cívico militares, los gérmenes de un ideario que se articula fragmentariamente a modo de diáspora relacional. Es decir, la competencia, como factor que cruza transversalmente a las universidades chilenas de todo tipo, han generado que, a pesar del reconocimiento de esas raíces históricas comunes, todas las universidades asuman un modo de comprender y publicitar su funcionalidad hacia los territorios, altamente heterogéneo, funcional a los recursos disponibles, que hace que el mapeo de experiencias tenga forma de una gran diáspora o explosión de sentidos y prácticas.

Los modelos que proponemos como equipo de investigación avanzan en ese reconocimiento plural. La Universidad, especialmente la pública, no es el lugar que quisiéramos que fuese. No existe democracia o participación interna, las autoridades siguen siendo electas por un grupo reducido de académicos, la disputa por matrículas cada año es feroz, seguimos enriqueciendo el mismo sistema que endeuda a nuestros estudiantes. Somos funcionales a determinados paradigmas tecnocráticos que esconden sus verdaderas orientaciones ideológicas. Pero, lejos de cualquier romanticismo anacrónico, el primer requisito es aceptar que esas son las condiciones de nuestras universidades y que, a pesar de todo ello, todavía la Vinculación con el medio/extensión universitaria sigue teniendo un espacio a lo largo y ancho de Chile. Eso lo demuestra precisamente la existencia de esos modelos que avanzan hacia un tercer tipo no reconocido en la literatura latinoamericana, que principalmente ha optado por la denominación dual: extensionismo difusionista o extensión crítica. Para nosotros hay entre ambos extremos existe una variedad de manifestaciones que explican la hibridez, poliformas, polifonías, heterogeneidades que hacen muy particular la situación de las universidades chilenas y de las comunidades que van encarando cada tanto el rol usurpador que a veces adquirimos a través del extractivismo académico. queue a veces adquiridmos a tray de las comunidades que van encarando cada tanto el rol usurpador que a veces adquiridmos a traFinalmente, se trata de un asunto de tiempo. O somos capaces de contextualizar a la Universidad con las nuevas exigencias que el contexto irá determinando: los cambios medio ambientales, las disputas territoriales, los saberes originarios, los populares, el neoliberalismo, la democracia desprestigiada, las universidades que funcionan como monarquías. O desaparecemos y juntos con nosotros aquellos valores que creemos imprescindibles para la vida. Como lo dijera alguna vez José Saramago:

"Disentir es un derecho que se encuentra y se encontrará inscrito con tinta invisible en todas las declaraciones de derechos humanos pasadas, presentes y futuras. Disentir es un acto irrenunciable de conciencias". (2009:450)

\section{Referencias bibliográficas}

Chile (2006). Ley N²0.129 Aseguramiento de la Calidad de la Educación Superior. Disponible en: https://www.cnachile.cl/Paginas/Ley\%2020129.aspx (consultado 17/05/2017).

Comisión Nacional de Acreditación (2017). Misión. Disponible en: https://www. cnachile.cl/Paginas/Ley\%2020129.aspx (consultado el 17/05/2017).

Carlevaro, P. (1998). Resumen informativo con perspectiva evaluativa sobre el programa APEX-Cerro. Montevideo: Universidad de la República.

Cesaire, A. (2016). Discurso sobre colonialismo. Madrid: Akal.

De Sousa Santos, B. (2009). Una epistemología del Sur. México: CLACSO. González, B. et al. (2017). Vinculación con el Medio y Territorio: Heterogeneidad de modelos, prácticas y sentidos en las universidades chilenas. Valparaíso: Observatorio de Participación Social y Territorio. Universidad de Playa Ancha. Ortiz-Riaga, M. C. y Morales-Rubiano, M. E. (2011). La extensión universitaria en América Latina: concepciones y tendencias. Educación y educadores, 14(2), 349-366.

Salazar, G. (2011). En el nombre del poder popular constituyente. Santiago de Chile: LOM ediciones.

Saramago, J. (2009). José Saramago en sus palabras. Madrid: Santillana.

Saravia, P. (2017). La generación de conocimiento compartido: Estrategias para la construcción de una universidad territorializada. Valparaíso: Observatorio de Participación Social y Territorio. Universidad de Playa Ancha.

Tommasino, H. (2010). De la extensión a las prácticas integrales. En UdelaR. Hacia la Reforma. La extensión en la transformación de la enseñanza: Los espacios en formación integral. Montevideo: Universidad de la República.

Tommasino, H. y Cano, A. (2016). Avances y retrocesos de la extensión crítica en la Universidad de la República de Uruguay. Masquedós, 1(1), 9-23 Tünnerman Bernhelm, C. (2003). La universidad latinoamericana ante los retos del siglo XXI. México: Unión de Universidades de América Latina. Tuhiwai, L. (2016). A descolonizar las metodologías. Investigación y pueblos indígenas. Santiago de Chile: LOM ediciones. 